\title{
Current Status of Noninvasive Ventilation Use in Korean Intensive Care Units: A Prospective Multicenter Observational Study
}

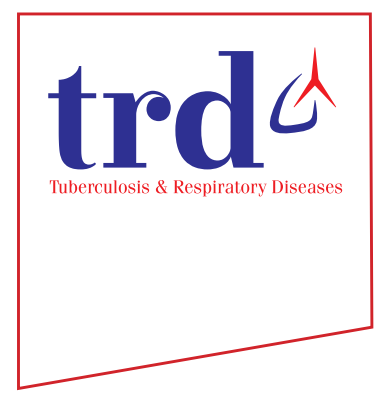

\author{
Hyunseung Nam, M.D. ${ }^{1}{ }^{(i)}$, Jae Hwa Cho, M.D., Ph.D. ${ }^{2}$, Eun Young Choi, M.D. ${ }^{3}$, Youjin Chang, M.D. , \\ Won-Il Choi, M.D., Ph.D. ${ }^{5}$, Jae Joon Hwang, M.D. ${ }^{6}$, Jae Young Moon, M.D., Ph.D. ${ }^{7}$ Kwangha Lee, \\ M.D. ${ }^{8}$, Sei Won Kim, M.D. ${ }^{9}$, Hyung Koo Kang, M.D. ${ }^{10}$, Yun Su Sim, M.D. ${ }^{11}$, Tai Sun Park, M.D. ${ }^{12}$, \\ Seung Yong Park, M.D. ${ }^{13}$ and Sunghoon Park, M.D., Ph.D. ${ }^{1}{ }^{(\mathbb{D}}$, on behalf of Korean NIV Study Group \\ *Author affiliations appear at the end of this article.
}

Background: Data on noninvasive ventilation (NIV) use in intensive care units (ICUs) are very limited in South Korea. Methods: A prospective observational study was performed in 20 ICUs of university-affiliated hospitals from June 2017 to February 2018. Adult patients (age>18 years) who were admitted to the ICU and received NIV treatment for acute respiratory failure were included.

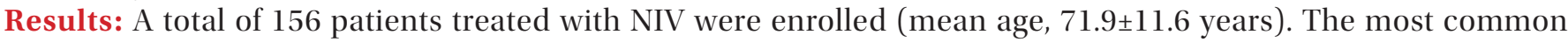
indications for NIV were acute hypercapnic respiratory failure (AHRF, $\mathrm{n}=89$ ) and post-extubation respiratory failure $(\mathrm{n}=44)$. The main device for NIV was an invasive mechanical ventilator with an NIV module (61.5\%), and the majority of patients (87.2\%) used an oronasal mask. After the exclusion of 32 do-not-resuscitate patients, NIV success rate was $68.5 \%$ (85/124); ICU and hospital mortality rates were $8.9 \%$ and $15.3 \%$, respectively. However, the success rate was lower in patients with de novo respiratory failure (27.3\%) compared to that of patients with AHRF (72.8\%) or post-extubation respiratory failure $(75.0 \%)$. In multivariate analysis, immunocompromised state, de novo respiratory failure, post-NIV (2 hours) respiratory rate, NIV mode (i.e., non-pressure support ventilation mode), and the change of NIV device were significantly associated with a lower success rate of NIV.

Conclusion: AHRF and post-extubation respiratory failure were the most common indications for NIV in Korean ICUs. Overall NIV success was achieved in $68.5 \%$ of patients, with the lowest rate in patients with de novo respiratory failure.

Keywords: Intensive Care Units; Noninvasive Ventilation; Masks

Address for correspondence: Sunghoon Park, M.D., Ph.D.

Department of Pulmonary, Allergy and Critical Care Medicine, Hallym University Sacred Heart Hospital, 22 Gwanpyeong-ro 170beon-gil,

Dongan-gu, Anyang 14068, Korea

Phone: 82-31-380-3715, Fax: 82-31-380-3973

E-mail:f2000tj@gmail.com

Received: Aug. 6, 2018

Revised: Oct. 29, 2018

Accepted: Nov. 22, 2018

Published online: Feb. 28, 2019

(c) It is identical to the Creative Commons Attribution Non-Commercial License (http://creativecommons.org/licenses/by-nc/4.0/).

\section{Introduction}

Noninvasive ventilation (NIV) is associated with decreased intubation and mortality rates in patients with acute exacerbation of chronic obstructive pulmonary disease (COPD) ${ }^{1}$ or cardiogenic pulmonary edema ${ }^{2}$. The treatment also plays a critical role in chronic respiratory failure of patients with a neuromuscular disease or chronic, severe and stable $\mathrm{COPD}^{3,4}$.

NIV has been used for various applications in clinical practice, such as to facilitate early weaning from invasive mechanical ventilation, for respiratory support after surgery ${ }^{5}$, during certain procedures $^{6}$, or as palliative therapy ${ }^{7}$. The use of NIV and its success rate are increasing ${ }^{8-10}$. However, the proportion of NIV use differs by region and patient condition ${ }^{10}$. In France, $39 \%$ of patients on a ventilator receive $\mathrm{NIV}^{11}$ whereas $20 \%$ of 
those on a ventilator in the New England region of the United States use $\mathrm{NIV}^{12}$. In Korea, one study reported that those receiving NIV accounted for $4 \%$ of all ventilated patients ${ }^{13}$.

The choice of mask is crucial for the success of NIV and it usually depends on considerations regarding patient comfort, air-leaks, and $\operatorname{cost}^{8}$. A facial (oronasal) mask is the most widely used method for patients with acute respiratory failure. However, helmets are increasingly being used in some countries $^{8}$. Although NIV use was not associated with an improved outcome in patients with de novo respiratory failure, a recent study showed that helmets were associated with reduced intubation and mortality rates in these patients ${ }^{14}$.

A few small studies have been conducted on NIV use in South Korea ${ }^{13,15}$ but the data are very limited. Therefore, in this multicenter study, we prospectively collected data on NIV use from patients being treated in Korean intensive care units (ICUs). We investigated the primary indications for NIV use and patient outcomes, as well as practice patterns, such as the NIV settings and type of interfaces used.

\section{Materials and Methods}

\section{Study population}

This was a prospective observational study performed in 20 ICUs of university-affiliated hospitals from June 1, 2017 to February 28, 2018. Adult patients (age $>18$ years) who were admitted to the ICUs and received NIV treatment for acute respiratory failure were prospectively enrolled. Among the indications for NIV, acute hypercapnic respiratory failure (AHRF) indicates respiratory failure in patients with chronic lung disease (obstructive or restrictive), and de novo respiratory failure usually indicates respiratory failure in patients without chronic respiratory disease, mostly those with hypoxemic respiratory failure, such as pneumonia, postoperative respiratory failure, sepsis, or acute respiratory distress syndrome $(\mathrm{ARDS})^{9,10}$. In our study, we included do-not-resuscitate (DNR) patients who received NIV, and the only exclusion criterion was refusal to provide informed consent for collection of clinical data.

This study was supported by a 2017 grant from the Korea Academy of Tuberculosis and Respiratory Diseases. The ethics committees from all participating hospitals approved this study, as did the Hallym University Institutional Review Board (approval no. 2017-I044). Informed consent was obtained from all enrolled patients or their legal surrogates.

\section{Data collection and outcomes}

We collected patient demographic information and the following data: comorbidities, underlying lung diseases, primary indications for NIV, and mental status (Richmond Agitation
Sedation Score [RASS]) and severity of illness (Sequential Organ Failure Assessment [SOFA]) immediately before starting NIV. We also assessed arterial blood gas analyses, as well as vital signs, before and 2 hours after NIV was started. We investigated the type of NIV machine (i.e., invasive mechanical ventilator [MV] with NIV module, invasive MV without NIV module, dedicated NIV ventilator, or home MV), the interfaces (i.e., oronasal, nasal or total facial masks, nasal pillow, or helmet), and the circuits (i.e., double limb circuit, single limb circuit with leak port, or single limb circuit with exhalation valve). We also investigated the NIV settings (main NIV modes, fractional inspired oxygen $\left[\mathrm{FiO}_{2}\right]$, inspiratory positive airway pressure [IPAP], expiratory positive airway pressure [EPAP], and estimated tidal volume) and their mean durations (hours/day).

After the exclusion of DNR patients, treatment success and failure, complications from NIV treatment, and ICU and hospital mortality rates were investigated as patient outcomes. Treatment success included successful weaning from NIV and successful transfer to the general ward in a stable condition with the NIV device in place. Treatment failure included (1) intubation and invasive MV, (2) tracheostomy, and (3) hopeless discharge with NIV device. Patients who died within 24 hours of NIV weaning were also classified as NIV failures. A large leak was defined when leak flow was $>60 \mathrm{~L} / \mathrm{min}$, or when the attending doctor considered it too large to allow the treatment continue.

The primary outcomes in this study were the NIV success rate and the common indications for NIV treatment in Korean ICUs. Secondary outcomes were the NIV settings, type of machine and interfaces used, and reasons for NIV failure.

\section{Statistical analysis}

In this study, descriptive analyses were primarily performed, because we were interested in the current status of NIV use. All categorical variables are presented as numbers with percentages, and all continuous variables are presented as means with standard deviations. Student's t test was used to compare continuous variables, and the chi-square or Fisher exact test was used to compare categorical variables. Logistic regression analysis was performed using covariates with a p-value of $<0.10$ on univariate analysis to identify independent factors for NIV success (and hospital survival); we employed a backward stepwise selection method based on the likelihood ratio. IBM SPSS for Windows software ver. 22.0 (IBM Corp., Armonk, NY, USA) was used for all statistical analyses. A p-value of $<0.05$ was considered significant. 


\section{Results}

\section{Study population and baseline characteristics}

A total of 168 patients treated with NIV were initially screened from 20 ICUs during the study period. Twelve patients refused to consent, and 156 were finally enrolled in the present study (Figure 1). The mean age was $71.9 \pm 11.6$ years and the mean body mass index was $21.6 \pm 5.3 \mathrm{~kg} / \mathrm{m}^{2}$. Diabetes $(\mathrm{n}=39)$ and hypertension $(\mathrm{n}=62)$ were the most common comorbidities. Of all patients, 118 (75.6\%) had underlying lung disease, with COPD ( $\mathrm{n}=60)$ and tuberculosis-destroyed lung $(\mathrm{n}=18)$ being the most common (Table 1). One hundred and forty-three patients $(91.7 \%)$ started NIV in the ICU and 13 started NIV in other places; 10 in general ward, one in emergency department, and two in other locations. The most common cause for starting NIV was AHRF $(\mathrm{n}=89,57.1 \%)$ (Figures $1,2)$, followed by post-extubation respiratory failure $(\mathrm{n}=44$, $28.2 \%)$. Of all patients, $59(37.8 \%)$ started high flow nasal cannula (HFNC) before NIV. At the time that NIV was started, the mean SOFA score was $4.2 \pm 2.7$ and the median RASS was 0.0 $(-1.0$ to 0.0$)$. Thirty-two DNR patients $(20.5 \%)$ were included in this study.

\section{NIV treatments (devices, modes, settings, and duration)}

Invasive MV with the NIV module was used in 96 patients (61.5\%), and invasive MV without the NIV module was used in two patients (1.3\%); a dedicated NIV machine (ICU use) was used in 33 patients $(21.2 \%)$, and a home MV was used by 25 patients (16.0\%). The dedicated NIV machine was

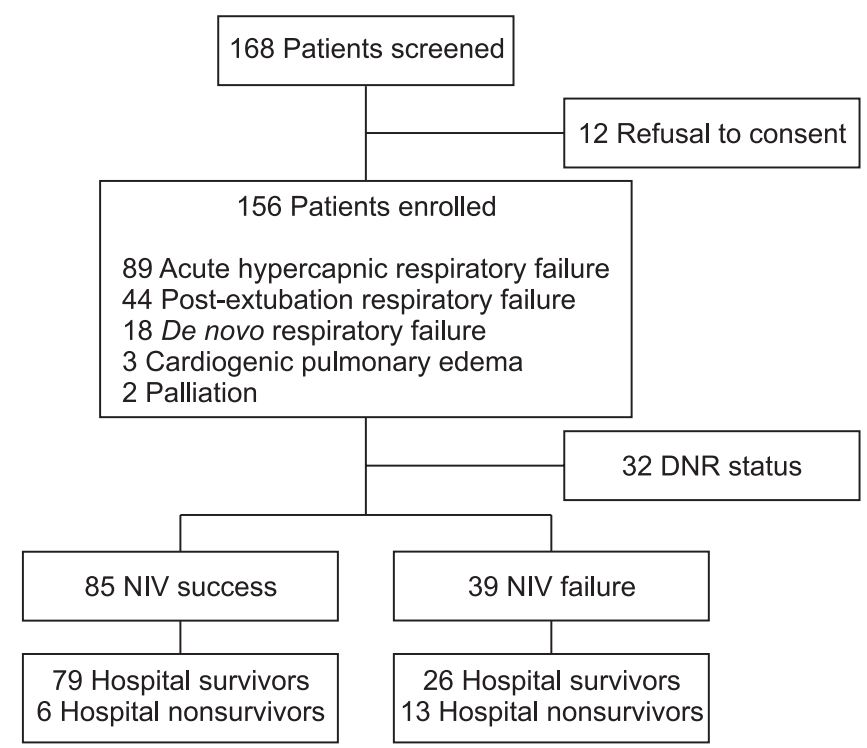

Figure 1. Flow chart of enrolled patients. NIV: noninvasive ventilation. most commonly used in patients with AHRF (57.6\%, 19/33). Among the NIV modes used, the pressure support ventilation (PSV, $\mathrm{n}=66$ ) and spontaneous/time (ST, $\mathrm{n}=48$ ) modes were the most commonly used; pressure-controlled ventilation in 36 , volume controlled ventilation in two, continuous positive airway pressure in two, and averaged volume-assured pressure support in two patients. The mean IPAP and EPAP values were $14.5 \pm 3.8$ and $5.0 \pm 1.5 \mathrm{~cm} \mathrm{H}_{2} \mathrm{O}$, respectively, and the estimated tidal volume was $499.6 \pm 198.3 \mathrm{ml}$. Daily NIV duration was 14.5 hours (6.0-22.0 hours), and total time on NIV was 3.0 days (1.0-6.0 days). Of all patients, 26 (16.7\%) received a sedative (or analgesic) during NIV treatment; remifentanil $(\mathrm{n}=15)$ and dexmedetomidine $(\mathrm{n}=8)$ were the most commonly used. The NIV device was changed to another device in 27 patients $(17.3 \%)$.

Table 1. Baseline characteristics

\begin{tabular}{|lc|}
\hline \multicolumn{1}{|c}{ Variable } & Value (n=156) \\
\hline Age, yr & $71.9 \pm 11.6$ \\
Male/female & $96 / 60$ \\
Body mass index, kg/m² & $21.6 \pm 5.3$ \\
SOFA score at NIV start & $4.2 \pm 2.7$ \\
\hline Comorbidities & \\
\hline Diabetes & $39(25.0)$ \\
\hline Hypertension & $62(39.7)$ \\
\hline Coronary artery disease & $20(12.8)$ \\
\hline Chronic heart failure & $34(21.8)$ \\
\hline Chronic kidney disease & $20(12.8)$ \\
\hline Cerebrovascular disease & $20(12.8)$ \\
\hline Liver cirrhosis & $7(4.5)$ \\
\hline Immunocompromised state & $22(14.1)$ \\
\hline Underlying lung/airway diseases & \\
\hline Chronic obstructive pulmonary disease & $60(38.5)$ \\
Bronchial asthma & $4(2.6)$ \\
\hline Tuberculosis-destroyed lung & $18(11.5)$ \\
\hline Bronchiectasis & $10(6.4)$ \\
\hline Interstitial lung disease & $6(3.8)$ \\
\hline Neuromuscular disease & $7(4.5)$ \\
\hline Chest wall disorder* & $5(3.2)$ \\
\hline Obesity & $5(3.2)$ \\
\hline Obstructive sleep apnea & $3(1.9)$ \\
Do-not-resuscitate state & $32(20.5)$ \\
\hline
\end{tabular}

Values are presented as mean \pm SD or number (\%).

*Includes kyphoscoliosis.

SOFA: sequential organ failure assessment; NIV: noninvasive ventilation. 


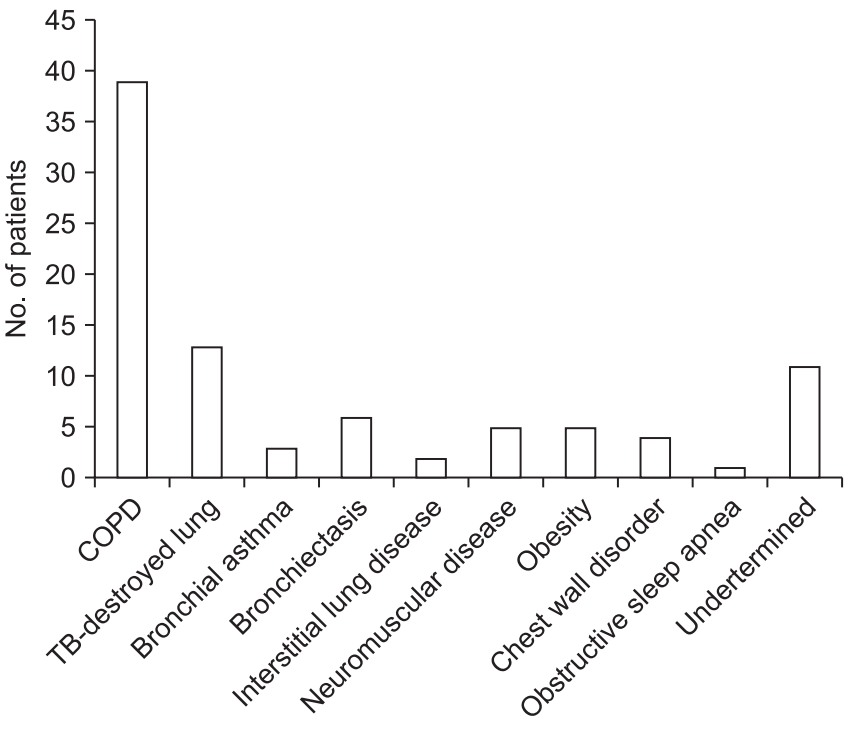

Figure 2. Underlying lung/airway diseases among 89 patients with acute hypercapnic respiratory failure. COPD: chronic obstructive pulmonary disease.

\section{Interfaces}

Among the interfaces used in this study, oronasal mask was the most commonly used $(n=136,87.2 \%)$, followed by a helmet $(n=12)$, a nasal mask $(n=4)$, a nasal pillow $(n=3)$, and a total facial mask $(n=1)$. Patients with AHRF, and those with post-extubation respiratory failure, used oronasal masks most frequently (91.0\% and $84.1 \%$, respectively). Among the circuit types used, a double limb circuit ( $\mathrm{n}=99)$ was most commonly used, while a single limb circuit with a leak port was used in 52 patients; a single limb circuit with exhalation valve was used by five patients. At least one mask change for any reason occurred during the treatment of 29 patients (18.6\%). Among the 12 patients with helmet, five patients used a helmet for post-extubation respiratory failure and four patients used it for AHRF; three patients for de novo respiratory failure. The most common mode used for helmet was PSV and pressurecontrolled ventilation ( $n=7$ and $n=3$, respectively), and after the exclusion of two DNR patients, NIV success was achieved in eight patients $(80.0 \%)$.

\section{Complications}

Complications of NIV were reported in 32 patients (20.5\%), with skin erythema $(n=26)$ being the most frequent. Other complications included abdominal distension $(n=7)$, dry mouth $(n=6)$, aspiration $(n=5)$, claustrophobia $(n=4)$, nasal congestion or sinus pain $(n=1)$, and mucus plugs $(n=1)$.

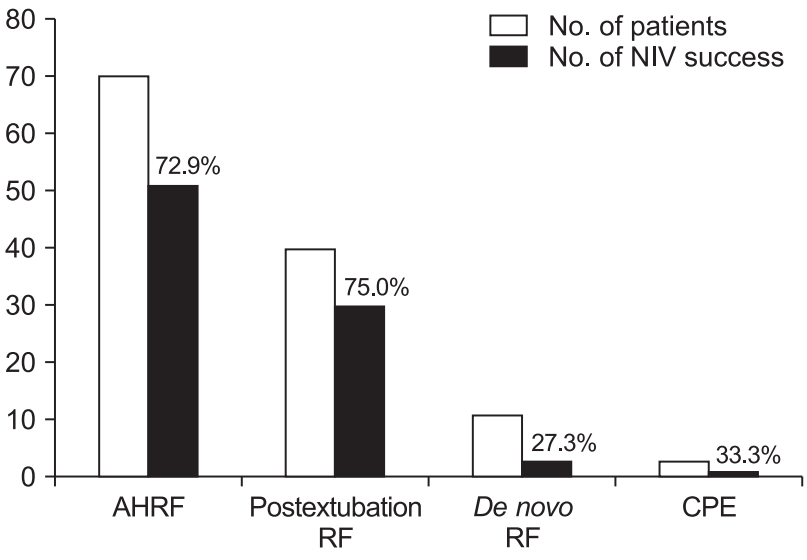

Figure 3. Primary indications for NIV ( $n=124)$. AHRF: acute hypercapnic respiratory failure; RF: respiratory failure; $\mathrm{CPE}$ : cardiogenic pulmonary edema; NIV: noninvasive ventilation.

Table 2. Reasons for NIV failure

\begin{tabular}{|lc|}
\hline \multicolumn{1}{|c|}{ Reason } & No. (\%) (n=39) \\
\hline Inadequate efficacy & \\
Absence of clinical improvement & $13(33.3)$ \\
Lack of arterial blood gas improvement & $14(35.9)$ \\
Copious secretion & $3(7.7)$ \\
Agitation & $1(2.6)$ \\
Large leak & $2(5.1)$ \\
Patients' discomfort or refuse & $6(15.4)$ \\
\hline
\end{tabular}

NIV: noninvasive ventilation.

\section{NIV outcomes}

Among 124 patients, NIV success was achieved in 85 (68.5\%) patients; 57 patients were successfully weaned from $\mathrm{NIV}$, and 28 were stabilized and transferred to the general ward on an NIV machine. Among the different indications, the NIV success rate was lower for de novo respiratory failure (27.3\%) compared to that for AHRF $(72.8 \%)$ or post-extubation respiratory failure $(75.0 \%)$ (Figure 3 ). Thirty-nine patients did not respond to NIV (i.e., treatment failure). Among them, 30 patients were intubated and conventionally ventilated, and six underwent tracheostomy (hopeless discharge with NIV in place, $n=3$ ). The reasons for NIV failure are shown in Table 2.

\section{Factors associated with NIV success and hospital survival}

Univariate analyses revealed that eight variables (i.e., immunocompromised state, de novo respiratory failure, nonPSV mode, NIV device change, NIV duration, pre-NIV $\mathrm{PaCO}_{2}$, post-NIV heart rate, and post-NIV respiratory rate) (Tables 3, 
4) were associated with NIV success, with a p-value of $<0.100$. In multivariate analysis, where age and gender were included, immunocompromised state, de novo respiratory failure, nonPSV mode, NIV device change, and a high post-NIV respiratory rate were significantly associated with a low success rate of NIV (Table 5).

Regarding hospital survival, seven variables (age, sex, SOFA score at NIV start, post-NIV heart rate, post-NIV respiratory rate, length of ICU stay, and NIV success) were selected from univariate analyses. Among them, NIV success was signifi-

Table 3. Comparisons in baseline and clinical parameters between patients with NIV success and patients with NIV failure $(\mathrm{n}=124)$

\begin{tabular}{|c|c|c|c|}
\hline Variable & NIV success $(n=85)$ & NIV failure $(n=39)$ & p-value \\
\hline Age, yr & $70.7 \pm 10.7$ & $70.7 \pm 12.9$ & 0.999 \\
\hline Male/female & $53 / 32$ & $16 / 13$ & 0.643 \\
\hline Body mass index, $\mathrm{kg} / \mathrm{m}^{2}$ & $22.4 \pm 5.9$ & $21.2 \pm 4.8$ & 0.249 \\
\hline \multicolumn{4}{|l|}{ Comorbidities } \\
\hline Diabetes & $22(25.9)$ & $12(30.8)$ & 0.571 \\
\hline Hypertension & $34(40.0)$ & $16(41.0)$ & 0.914 \\
\hline Coronary artery disease & $8(9.4)$ & $5(12.8)$ & 0.565 \\
\hline Chronic heart failure & $16(18.8)$ & $9(23.1)$ & 0.584 \\
\hline Chronic kidney disease & $9(16.1)$ & $8(20.5)$ & 0.136 \\
\hline Cerebrovascular disease & $10(11.8)$ & $4(10.3)$ & 0.805 \\
\hline Liver cirrhosis & $3(3.5)$ & $2(5.1)$ & 0.674 \\
\hline Immunocompromised state & $1(1.2)$ & $5(12.8)$ & 0.005 \\
\hline Underlying lung/airway diseases & & & 0.300 \\
\hline No underlying disease & $16(18.8)$ & $13(33.3)$ & \\
\hline Obstructive lung diseases* & $51(60.0)$ & $18(46.2)$ & \\
\hline 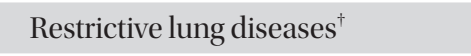 & $14(16.5)$ & $7(17.9)$ & \\
\hline Others $^{*}$ & $4(4.7)$ & $1(2.6)$ & \\
\hline \multicolumn{4}{|l|}{ Indications of NIV start } \\
\hline AHRF & $51(60.0)$ & $19(48.7)$ & 0.239 \\
\hline De novo respiratory failure & $3(3.5)$ & $8(20.5)$ & 0.002 \\
\hline Cardiogenic pulmonary edema & $1(1.2)$ & $2(5.1)$ & 0.233 \\
\hline Post-extubation respiratory failure & $30(35.3)$ & $10(25.6)$ & 0.286 \\
\hline SOFA score at NIV start & $3.9 \pm 2.2$ & $4.5 \pm 2.7$ & 0.219 \\
\hline RASS at NIV start & $-0.3 \pm 0.9$ & $-0.3 \pm 1.0$ & 0.863 \\
\hline HFNC before NIV start & $24(28.2)$ & $16(41.0)$ & 0.157 \\
\hline PSV mode & $42(49.4)$ & $10(25.6)$ & 0.013 \\
\hline NIV device change & $11(12.9)$ & $13(33.3)$ & 0.008 \\
\hline Use of helmet & $8(9.4)$ & $2(5.1)$ & 0.503 \\
\hline NIV duration, day & $4.6 \pm 3.4$ & $2.8 \pm 4.5$ & 0.018 \\
\hline Large air leaks & $7(8.2)$ & $5(12.8)$ & 0.423 \\
\hline NIV complications & $21(24.7)$ & $11(28.2)$ & 0.697 \\
\hline
\end{tabular}

Values are presented as mean \pm SD or number (\%).

${ }^{*}$ Chronic obstructive pulmonary disease $(n=45)$, bronchial asthma $(n=2)$, tuberculosis-destroyed lung $(n=13)$, and bronchiectasis $(n=7)$. 'Interstitial lung disease $(\mathrm{n}=4)$, neuromuscular disease $(\mathrm{n}=6)$, obesity $(\mathrm{n}=5)$, and chest wall disorders $(\mathrm{n}=6) .{ }^{*}$ Obesity sleep apnea $(\mathrm{n}=3)$ and undetermined $(\mathrm{n}=2)$.

NIV: noninvasive ventilation; AHRF: acute hypercapnic respiratory failure; SOFA: Sequential Organ Failure Assessment; RASS: Richmond Agitation Sedation Scale; HFNC: high flow nasal cannula; PSV: pressure-support ventilation; SD: standard deviation. 
cantly associated with hospital survival in multivariate analysis (Table 5).

\section{Discussion}

This is the first prospective study on current NIV use in Korean ICUs, and patients from 20 university-affiliated hospitals across the nation were included. Our study had several main findings. First, the most common indications for starting NIV were AHRF (57.1\%) and post-extubation respiratory failure (28.2\%); the proportion of patients using NIV for de novo respiratory failure was lower (11.5\%). Second, NIV success was achieved in $68.5 \%$ of patients, and de novo respiratory failure had a relatively low success rate among the NIV indications. Third, the main device for NIV was the invasive MV with the NIV module (61.5\%), and the majority of patients (87.2\%) used an oronasal mask.

The rate of NIV use varies by country and hospital, but recent studies have reported an increase in the rate of NIV use. Overall NIV use in a French study increased to $37 \%$ in 2010-2011, compared to $16 \%$ (1997) and 28\% (2002) during earlier periods ${ }^{9}$. In Spain, the NIV use rate increased from 0.4 per 100,000 (1997) to 15.1 per 100,000 hospitalized patients (2010), in contrast to a decrease in the use of invasive $\mathrm{MV}^{16}$. In a regional survey of North America, $20 \%$ of ventilated patients received NIV, with the rate ranging from $0 \%$ to $55 \%$ among different hospitals ${ }^{12}$. In particular, NIV was started most often in the emergency department in some regions ${ }^{17}$, which was in contrast to our study where only one patient started NIV in the emergency department.

The most common indications for NIV have been acute exacerbation of COPD and cardiogenic pulmonary edema; in French studies, they accounted for $>40 \%$ and $>20 \%$, respectively, of NIV indications ${ }^{8-10,12,17}$. These results could be due to proven efficacy in randomized controlled trials ${ }^{1,2}$. The current guidelines still strongly recommend NIV for these patient groups ${ }^{18}$. In our study, AHRF was the most common indication, followed by post-extubation respiratory failure and de novo hypoxemia. A European survey reported that postextubation respiratory failure was the second most common indication in Germany and the United Kingdom ${ }^{8}$, and a recent French study also demonstrated a substantial increase in NIV use in this population ${ }^{9}$. Based on previous multicenter randomized studies, NIV may reduce re-intubation and mortality rates when applied immediately after planned extubation in selected patients at high-risk for respiratory failure ${ }^{19,20}$. However, NIV is not recommended in patients without COPD and with established post-extubation respiratory failure ${ }^{18}$.

In our study, the proportion of NIV use for de novo respiratory failure was lower compared to other indications (i.e., AHRF and post-extubation respiratory failure), in keeping with previous studies ${ }^{9,11}$, but the NIV failure rate was higher. Although NIV could be beneficial in selected patients, in-

Table 4. Comparisons in vital signs and arterial blood gas results between patients with NIV success and patients with NIV failure $(n=124)$

\begin{tabular}{|c|c|c|c|}
\hline Variable & NIV success $(n=85)$ & NIV failure $(n=39)$ & p-value \\
\hline \multicolumn{4}{|l|}{ Before NIV start } \\
\hline $\mathrm{pH}$ & $7.37 \pm 0.1$ & $7.38 \pm 0.9$ & 0.769 \\
\hline $\mathrm{PaO}_{2} / \mathrm{FiO}_{2}$ ratio & $227.8 \pm 96.0$ & $214.4 \pm 107.2$ & 0.488 \\
\hline $\mathrm{PaCO}_{2}, \mathrm{~mm} \mathrm{Hg}$ & $60.5 \pm 20.1$ & $54.5 \pm 16.0$ & 0.099 \\
\hline Systolic blood pressure, $\mathrm{mm} \mathrm{Hg}$ & $130.1 \pm 26.5$ & $129.0 \pm 25.1$ & 0.835 \\
\hline Heart rate, /min & $92.8 \pm 17.8$ & $98.1 \pm 25.3$ & 0.187 \\
\hline Respiratory rate, /min & $24.2 \pm 6.1$ & $25.8 \pm 6.9$ & 0.199 \\
\hline Body temperature, ${ }^{\circ} \mathrm{C}$ & $36.8 \pm 0.4$ & $36.9 \pm 0.5$ & 0.275 \\
\hline \multicolumn{4}{|l|}{ After NIV start (2 hr) } \\
\hline $\mathrm{pH}$ & $7.40 \pm 0.1$ & $7.39 \pm 0.1$ & 0.718 \\
\hline $\mathrm{PaO}_{2} / \mathrm{FiO}_{2}$ ratio & $245.3 \pm 84.5$ & $223.7 \pm 87.4$ & 0.198 \\
\hline $\mathrm{PaCO}_{2}, \mathrm{~mm} \mathrm{Hg}$ & $54.2 \pm 15.6$ & $49.5 \pm 16.6$ & 0.135 \\
\hline Systolic blood pressure, mm Hg & $125.0 \pm 21.9$ & $129.9 \pm 23.9$ & 0.272 \\
\hline Heart rate, /min & $89.3 \pm 16.9$ & $95.8 \pm 17.9$ & 0.054 \\
\hline Respiratory rate, /min & $22.6 \pm 5.1$ & $25.8 \pm 6.4$ & 0.010 \\
\hline Body temperature, ${ }^{\circ} \mathrm{C}$ & $36.8 \pm 0.5$ & $36.8 \pm 0.5$ & 0.828 \\
\hline
\end{tabular}

NIV: noninvasive ventilation; $\mathrm{PaO}_{2}$ : arterial oxygen tension; $\mathrm{FiO}_{2}$ : fraction of inspired oxygen; $\mathrm{PaCO}_{2}$ : arterial carbon dioxide tension. 
Table 5. Multivariate analyses for NIV success and hospital survival

\begin{tabular}{|c|c|c|c|c|c|c|}
\hline \multirow{2}{*}{ Variable } & \multicolumn{3}{|c|}{ NIV success* } & \multicolumn{3}{|c|}{ Hospital survival $^{\dagger}$} \\
\hline & p-value & ORs & $95 \% \mathrm{CI}$ & p-value & ORs & $95 \%$ CI \\
\hline Age & - & - & - & 0.051 & 0.933 & $0.870-1.000$ \\
\hline Immunocompromised & 0.014 & 0.041 & $0.003-0.524$ & - & - & - \\
\hline De novo respiratory failure & 0.020 & 0.105 & $0.016-0.697$ & - & - & - \\
\hline SOFA score at NIV start & - & - & - & 0.080 & 0.804 & $0.630-1.026$ \\
\hline PSV mode & 0.003 & 5.663 & $1.809-17.734$ & - & - & - \\
\hline Heart rate (post-2 hr NIV) & - & - & - & 0.066 & 0.971 & $0.941-1.002$ \\
\hline Respiratory rate (post-2 hr NIV) & 0.014 & 0.894 & $0.817-0.978$ & 0.064 & 0.906 & $0.816-1.006$ \\
\hline NIV device change & 0.009 & 0.221 & $0.072-0.684$ & - & - & - \\
\hline NIV duration, day & 0.076 & 1.155 & $0.985-1.356$ & - & - & - \\
\hline NIV success & - & - & - & 0.021 & 3.983 & $1.227-12.93$ \\
\hline
\end{tabular}

*Hosmer-lemeshow test: chi-square=11.503 and $\mathrm{p}=0.175$. ${ }^{\dagger}$ Hosmer-lemeshow test: chi-square=9.892 and $\mathrm{p}=0.273$.

NIV: noninvasive ventilation; OR: odds ratio; CI: confidence interval; SOFA: Sequential Organ Failure Assessment; PSV: pressure-support ventilation.

sufficient evidence supports its use for de novo respiratory failure $^{18}$. Particularly, NIV failure in this group was associated with a higher mortality rate compared to first-line invasive ventilation $^{21}$. The effect of NIV on reducing the work of breathing remains uncertain ${ }^{22}$ and high transpulmonary pressure may aggravate lung injury ${ }^{23}$. However, HFNC may be promising in selected patients with de novo respiratory failure ${ }^{24,25}$. In our study, 11 patients $(61.1 \%)$ with de novo respiratory failure received HFNC before NIV.

The invasive MV with the NIV module was used in $61.5 \%$ of patients, similar to the rate in France. However, in other countries, the use of a dedicated NIV ventilator was more frequent $\left(41.2 \%\right.$ in the United Kingdom and $37.5 \%$ in Germany) ${ }^{8}$. Although the frequencies differed by hospital and country, it is important that physicians are aware that asynchrony can occur more frequently among invasive $\mathrm{MVs}^{26}$, and many invasive MVs may need to be adjusted if a large leak occurs ${ }^{27}$. Among NIV modes, pressure support modes (PSV and ST) were the most widely used in our study, but the applied levels of pressure support and positive end expiratory pressure (PEEP) were not different from other studies.

The oronasal mask was the most commonly used (87.2\%) device, similar to data from other countries ${ }^{8,10,12}$; helmets were used by 12 patients (7.7\%). A European survey reported that helmets were used in $<10 \%$ of patients, whereas $29.9 \%$ of Italian patients with ARDS used helmets ${ }^{28}$. Reports on the effects of NIV on patients with ARDS are conflicting. However, based on recent studies, NIV (via helmet) might be beneficial in these populations once optimal PEEP levels with less leakage have been obtained via interfaces ${ }^{14,29}$.

In a regional survey conducted in the United States, the estimated success rate was $51.1 \%$, and the NIV success rate increased from $56.0 \%$ (2002) to $70.0 \%$ (2010/2011) in France.
Although the NIV success rate (68.5\%) was not markedly higher in our study compared to other investigations, the daily NIV duration was longer at 14.5 hours (6.0-22.0 hours). However, we did not investigate patients who prematurely discontinued NIV and survived without intubation, but we classified patients who became clinically stable and were transferred to the general ward with a NIV device as the NIV success group. This finding should be considered when our results are interpreted.

These days, NIV use and its success rates are increasing. In particular, the survival rate in those receiving NIV for de novo respiratory failure has increased in France. This may be because of trends toward better patient selection and greater proficiency of physicians ${ }^{9}$. However, given the substantial complication and treatment failure rates of NIV, physician experience and adequate staff training seem to be crucial ${ }^{12,30}$.

Several limitations to our study should be mentioned. First, we could not investigate trends in overall NIV use or the distribution of NIV indications over time. In particular, data on the NIV use during spring time were not investigated in this study. Second, we did not include patients who received NIV outside the ICU, so it is possible that NIV use in the hospitals may have been underestimated. Third, the criteria for starting NIV may have differed among hospitals. However, we were interested in the current practices of NIV use in Korean ICUs. Finally, we could not involve all ICUs in Korea, and the number of patients enrolled in this study was not large enough to draw a definite conclusion. Hence, further large-scale studies will be needed in the future.

In conclusion, our study revealed that the most common indications for starting NIV were AHRF and post-extubation respiratory failure in Korean ICUs, and the overall NIV success rate was $68.5 \%$. Although the proportion of patients receiving 
NIV for de novo respiratory failure was lower, their failure rate was higher compared to other indications. Future comprehensive studies on overall trends in NIV use and its indications, as well as on factors affecting NIV outcomes, are needed.

\section{*Author Affiliations}

${ }^{1}$ Department of Pulmonary, Allergy and Critical Care Medicine, Hallym University Sacred Heart Hospital, Anyang, ${ }^{2}$ Department of Internal Medicine, Gangnam Severance Hospital, Yonsei University College of Medicine, Seoul, ${ }^{3}$ Department of Pulmonary and Critical Care Medicine, Yeungnam University Hospital, Daegu, ${ }^{4}$ Department of Pulmonary and Critical Care Medicine, Inje University Sanggye Paik Hospital, Seoul, ${ }^{5}$ Department of Internal Medicine, Kyeimyung University Dongsan Hospital, Daegu, ${ }^{6}$ Department of Pulmonary and Critical Care Medicine, Kyung Hee University Hospital at Gangdong, Seoul, ${ }^{7}$ Department of Pulmonary and Critical Care Medicine, Chungnam University Hospital, Daejeon, ${ }^{8}$ Department of Internal Medicine, Pusan National University Hospital, Busan, ${ }^{9}$ Department of Pulmonary, Critical Care and Sleep Medicine, St. Paul's Hospital, College of Medicine, The Catholic University of Korea, Seoul, ${ }^{10}$ Division of Pulmonary and Critical Care Medicine, Department of Internal Medicine, Inje University Ilsan Paik Hospital, Goyang, ${ }^{11}$ Department of Pulmonary, Allergy and Critical Care Medicine, Hallym University Kangnam Sacred Heart Hospital, Seoul, ${ }^{12}$ Department of Internal Medicine, Hanyang University Guri Hospital, Guri, ${ }^{13}$ Department of Pulmonary, Allergy and Critical Care Medicine, Chonbuk National University Hospital, Jeonju, Korea

\section{Authors' Contributions}

Conceptualization: Nam H, Cho JH, Choi EY, Chang Y, Hwang JJ, Sim YS, Park S. Methodology: Sim YS, Moon JY, Lee K, Choi WI, Hwang JJ, Park SY, Park TS, Kim SW, Kang HK, Park S. Formal analysis: Nam H, Choi EY, Chang Y, Park TS, Moon JY, Park SY, Kim SW, Kang HK, Park S. Writing - original draft preparation: Nam H, Cho JH, Choi WI, Lee K, Park S. Writing - review and editing: Nam H, Cho JH, Choi EY, Chang Y, Choi WI, Hwang JJ, Moon JY, Lee K, Kim SW, Kang HK, Sim YS, Park TS, Park SY, Park S. Approval of final manuscript: all authors.

\section{Conflicts of Interest}

No potential conflict of interest relevant to this article was reported.

\section{Acknowledgments}

This work was supported by a 2017 research grant from the Korea Academy of Tuberculosis and Respiratory Disease. The funders had no role in study design, data collection and analysis, preparation. We thank the following investigators for the participation in this study: Jin Woo Kim (The Catholic University of Korea, Uijeongbu St. Mary's Hospital), Jong Hoo Lee (Jeju National University Hospital), Tae Oak Kim (Chonnam National University Hospital), Yun Mi Sin (Chungbuk National University), and Jik Hwan Ha (The Catholic University of Korea, Incheon St. Mary's Hospital).

\section{References}

1. Brochard L, Mancebo J, Wysocki M, Lofaso F, Conti G, Rauss A, et al. Noninvasive ventilation for acute exacerbations of chronic obstructive pulmonary disease. N Engl J Med 1995; 333:817-22.

2. Gray A, Goodacre S, Newby DE, Masson M, Sampson F, Nicholl J, et al. Noninvasive ventilation in acute cardiogenic pulmonary edema. N Engl J Med 2008;359:142-51.

3. Bourke SC, Tomlinson M, Williams TL, Bullock RE, Shaw PJ, Gibson GJ. Effects of non-invasive ventilation on survival and quality of life in patients with amyotrophic lateral sclerosis: a randomised controlled trial. Lancet Neurol 2006;5:140-7.

4. Kohnlein T, Windisch W, Kohler D, Drabik A, Geiseler J, Hartl $\mathrm{S}$, et al. Non-invasive positive pressure ventilation for the treatment of severe stable chronic obstructive pulmonary disease: a prospective, multicentre, randomised, controlled clinical trial. Lancet Respir Med 2014;2:698-705.

5. Zarbock A, Mueller E, Netzer S, Gabriel A, Feindt P, KindgenMilles D. Prophylactic nasal continuous positive airway pressure following cardiac surgery protects from postoperative pulmonary complications: a prospective, randomized, controlled trial in 500 patients. Chest 2009;135:1252-9.

6. Murgu SD, Pecson J, Colt HG. Bronchoscopy during noninvasive ventilation: indications and technique. Respir Care 2010; 55:595-600.

7. Nava S, Ferrer M, Esquinas A, Scala R, Groff P, Cosentini R, et al. Palliative use of non-invasive ventilation in end-of-life patients with solid tumours: a randomised feasibility trial. Lancet Oncol 2013;14:219-27.

8. Crimi C, Noto A, Princi P, Esquinas A, Nava S. A European survey of noninvasive ventilation practices. Eur Respir J 2010; 36:362-9.

9. Demoule A, Chevret S, Carlucci A, Kouatchet A, Jaber S, Meziani F, et al. Changing use of noninvasive ventilation in critically ill patients: trends over 15 years in francophone countries. Intensive Care Med 2016;42:82-92.

10. Demoule A, Girou E, Richard JC, Taille S, Brochard L. Increased use of noninvasive ventilation in French intensive 
care units. Intensive Care Med 2006;32:1747-55.

11. Schnell D, Timsit JF, Darmon M, Vesin A, Goldgran-Toledano D, Dumenil AS, et al. Noninvasive mechanical ventilation in acute respiratory failure: trends in use and outcomes. Intensive Care Med 2014;40:582-91.

12. Maheshwari V, Paioli D, Rothaar R, Hill NS. Utilization of noninvasive ventilation in acute care hospitals: a regional survey. Chest 2006;129:1226-33.

13. Hong SB, Oh BJ, Kim YS, Kang EH, Kim CH, Park YB, et al. Characteristics of mechanical ventilation employed in intensive care units: a multicenter survey of hospitals. J Korean Med Sci 2008;23:948-53.

14. Patel BK, Wolfe KS, Pohlman AS, Hall JB, Kress JP. Effect of noninvasive ventilation delivered by helmet vs face mask on the rate of endotracheal intubation in patients with acute respiratory distress syndrome: a randomized clinical trial. JAMA 2016;315:2435-41.

15. Yoo JW, Synn A, Huh JW, Hong SB, Koh Y, Lim CM. Clinical efficacy of high-flow nasal cannula compared to noninvasive ventilation in patients with post-extubation respiratory failure. Korean J Intern Med 2016;31:82-8.

16. Carpe-Carpe B, Hernando-Arizaleta L, Ibanez-Perez MC, Palomar-Rodriguez JA, Esquinas-Rodriguez AM. Evolution of the use of noninvasive mechanical ventilation in chronic obstructive pulmonary disease in a Spanish region, 1997-2010. Arch Bronconeumol 2013;49:330-6.

17. Sinuff T, Cook D, Randall J, Allen C. Noninvasive positivepressure ventilation: a utilization review of use in a teaching hospital. CMAJ 2000;163:969-73.

18. Rochwerg B, Brochard L, Elliott MW, Hess D, Hill NS, Nava S, et al. Official ERS/ATS clinical practice guidelines: noninvasive ventilation for acute respiratory failure. Eur Respir J 2017; 50:1602426.

19. Ferrer M, Valencia M, Nicolas JM, Bernadich O, Badia JR, Torres A. Early noninvasive ventilation averts extubation failure in patients at risk: a randomized trial. Am J Respir Crit Care Med 2006;173:164-70.

20. Nava S, Gregoretti C, Fanfulla F, Squadrone E, Grassi M, Car- lucci A, et al. Noninvasive ventilation to prevent respiratory failure after extubation in high-risk patients. Crit Care Med 2005;33:2465-70.

21. Demoule A, Girou E, Richard JC, Taille S, Brochard L. Benefits and risks of success or failure of noninvasive ventilation. Intensive Care Med 2006;32:1756-65.

22. Viires N, Sillye G, Aubier M, Rassidakis A, Roussos C. Regional blood flow distribution in dog during induced hypotension and low cardiac output: spontaneous breathing versus artificial ventilation. J Clin Invest 1983;72:935-47.

23. Kallet RH, Diaz JV. The physiologic effects of noninvasive ventilation. Respir Care 2009;54:102-15.

24. Dysart K, Miller TL, Wolfson MR, Shaffer TH. Research in high flow therapy: mechanisms of action. Respir Med 2009; 103:1400-5.

25. Frat JP, Thille AW, Mercat A, Girault C, Ragot S, Perbet S, et al. High-flow oxygen through nasal cannula in acute hypoxemic respiratory failure. N Engl J Med 2015;372:2185-96.

26. Carteaux G, Lyazidi A, Cordoba-Izquierdo A, Vignaux L, Jolliet P, Thille AW, et al. Patient-ventilator asynchrony during noninvasive ventilation: a bench and clinical study. Chest 2012;142:367-76.

27. Ferreira JC, Chipman DW, Hill NS, Kacmarek RM. Bilevel vs ICU ventilators providing noninvasive ventilation: effect of system leaks: a COPD lung model comparison. Chest 2009; 136:448-56.

28. Antonelli M, Conti G, Esquinas A, Montini L, Maggiore SM, Bello G, et al. A multiple-center survey on the use in clinical practice of noninvasive ventilation as a first-line intervention for acute respiratory distress syndrome. Crit Care Med 2007; 35:18-25.

29. Tucci MR, Costa EL, Nakamura MA, Morais CC. Noninvasive ventilation for acute respiratory distress syndrome: the importance of ventilator settings. J Thorac Dis 2016;8:E982-6.

30. Girou E, Brun-Buisson C, Taille S, Lemaire F, Brochard L. Secular trends in nosocomial infections and mortality associated with noninvasive ventilation in patients with exacerbation of COPD and pulmonary edema. JAMA 2003;290:2985-91. 